\title{
Air quality, climate change and resilience in the Porto urban area
}

\author{
C. Borrego, H. Martins, J. H. Amorim, S, Freitas \& A. I. Miranda \\ CESAM and Department of Environment and Planning, \\ University of Aveiro, Portugal
}

\begin{abstract}
The combined effect of global climate change and urban growth makes people in cities more vulnerable to environmental problems like extreme weather and poor air quality. Project CLICURB aims at assessing the impact of future climate on urban areas and how cities can adapt to reduce exposure and sensitivity to those impacts. CLICURB focuses on Porto, a European urban area experiencing accelerated rates of urbanization and simultaneously presenting poor air quality.

In the framework of one of CLICURB's tasks, regarding the implementation and effectiveness of adaptation measures, the WRF-UCM-CAMx numerical modelling system was used to evaluate the effects of the expansion of Porto's City Park on meteorology and air quality. Two high spatial resolution simulations were conducted for the study area, current and expanded, for a twoday period contained in a heat wave. Results indicate that the expansion improves local microclimatic conditions, with temperature decreases and slight increases in wind speed; regarding air quality, ground-level concentrations of pollutants present negligible variations.

The project also aims to assess the effects of wind dynamics and streetcanyon configuration on pedestrian comfort. For this purpose, a micro-scale modelling approach, based on the application of Computational Fluid Dynamics (CFD) model Fluent ${ }^{\circledR}$, was carried out for a study area with approximately $600 \mathrm{x}$ $600 \mathrm{~m}^{2}$. Eight typical meteorological situations were defined based on climate observation analysis. Results allow the identification of areas non-compliant with an international criterion for human comfort and where measures for mitigating the wind speed would improve conditions for outdoor activities.

Keywords: climate change, resilience, air quality, human comfort.
\end{abstract}




\section{Introduction}

The growth of urbanization and urban population is expected to continue over the next decades: according to the UN [1] it is projected that, by $2030,60 \%$ of the world population will be urban. The combined effect of global climate change (CC) and urban growth make people in cities more vulnerable to a number of environmental problems including extreme weather and poor air quality (AQ).

The urban heat island (UHI) phenomenon [2] is already well known and documented: the urban areas have higher temperatures when compared with adjacent rural areas. The higher temperatures in urban areas are in turn prone to the occurrence of episodes of air pollution, promoting situations of stagnant atmospheric circulation and formation of photochemical pollutants, such as tropospheric ozone. Currently, urban green infrastructures are the subject of redoubled interest, due to their potential in mitigating increasing temperatures as a result of CC. In fact, the layer of warm air developed over the city is interrupted by the effect of intra-urban land uses such as parks, lakes and open areas, forming "cool pools" [3]. Green areas use much of the absorbed energy in processes of evapotranspiration and water vapour release, thus contributing to the cooling of the air. Additionally, the pressure gradient induced by the temperature difference between the different land uses (green and urban), causes the advection of the fresh air from the green zone to the urbanized area.

Numerical modelling is a powerful tool for air quality evaluation and management. Its application has been defined and recommended throughout EU's air quality legislation, namely in the Air Quality Directive 2008/50/EC. Modelling may be used as a tool to supplement monitoring data for assessment purposes when reporting exceedances of AQ standards, it is also an important complementary tool on which to base action plans, both short and long term, and is currently used extensively in AQ forecasts [4].

There are already several studies on the impact of $\mathrm{CC}$ at European level; however, the air quality/climate interactions have been studied primarily at global and regional scales, with spatial resolutions too coarse and therefore unable to capture the urban characteristics. The main objective of CLICURB is the evaluation of the impact of CC in urban areas, using as case study the Porto urban area. The work here presented concerns one of CLICURB's tasks, regarding the implementation and effectiveness of adaptation measures. The present work examines the microclimatic and air quality effects of expanding an existent urban green area in the city of Porto through numerical simulations conducted with an urbanized mesoscale modelling system. The second example concerns the analysis of the effects of wind dynamics and street-canyon configuration on pedestrian comfort. For this purpose, a micro-scale modelling approach, based on the application of a Computational Fluid Dynamics (CFD) model, was carried out. 


\section{Urban green areas}

\subsection{Methodology}

\subsubsection{Modelling tools}

The WRF (Weather Research and Forecasting) model is a fully compressible non-hydrostatic model with a mass coordinate system which has been developed for research and operational applications [5]. Recently in WRF, the community Noah land surface model has been coupled with different urban canopy models. In this study, the single-layer urban canopy model (SLUCM) was applied. Using the two-way nesting approach, the WRF model was applied to four domains with the following characteristics: a first domain (D1) over SW Europe with 110x80 horizontal cells and a horizontal resolution of $25 \mathrm{~km}$, D2 covering Mainland Portugal with 100x140 cells and $5 \mathrm{~km}$ resolution, D3 over the Porto Metropolitan Area with $60 \times 65$ cells and $1 \mathrm{~km}$ resolution, and D4 centred in the city of Porto with $45 \times 45$ cells and $0.5 \mathrm{~km}$ resolution (Figure 1 ).
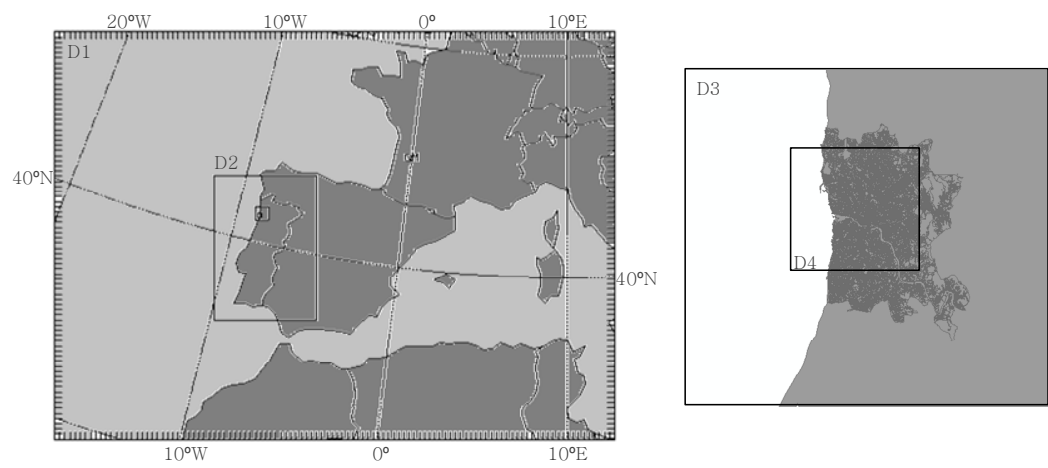

Figure 1: WRF modelling domains, from $25 \mathrm{~km}$ resolution over Southwestern Europe to $0.5 \mathrm{~km}$ over the city of Porto.

Following the WRF default options, land use data (24-category classification) from the U.S. Geological Survey (USGS) data base was applied to the larger domain. The land use for domains 2 and 3, covering Portugal and the Porto Metropolitan Area, were taken from Corine Land Cover, and for D4, over the city, data from the Urban Atlas from the European Environment Agency was used.

The Comprehensive Air Quality Model with Extensions (CAMx) photochemical grid model [6] is a photochemical Eulerian dispersion model that simulates the emission, dispersion, chemical reactions and the removal of pollutants in the atmosphere by solving the continuity equation for each chemical species in a system of three-dimensional meshes. CAMx was applied to three domains corresponding to WRF's domains D2 to D4, albeit with slightly smaller dimensions, but with the same spatial resolutions. Emissions for Spain were taken from EMEP-EU27 gridded emissions; for Portugal, the national emission 
inventory developed for regulatory purposes was used. Emissions were provided by the SNAP category for $\mathrm{CO}, \mathrm{NH}_{3}$, NMVOC, SOx, PM2.5 and PM10.

\subsubsection{Study period}

As period of study, $31^{\text {st }}$ July and $1^{\text {st }}$ August 2003, contained in the heat wave that occurred in Portugal (and Europe), were selected. According to Vautard et al. [7], the summer of 2003 provides a powerful case study for anticipating the impacts of summertime climate change in Europe.

\subsubsection{Study area}

Southern Europe's urban areas are experiencing a change towards a more dispersed growth at the expense of agricultural and forested land [20]. In the recently published EEA report 'Urban adaptation to climate change in Europe' [8], Porto stands out as the Portuguese urban area with the least share of green and blue areas, which together with the foreseen increase in the number of tropical nights and hot days in the future, will likely intensify the UHI effect. Additionally, according to the region's Air Quality (AQ) reports, the Porto metropolitan area presents poor AQ [9].

In this study, the City Park was selected as the urban green area to expand in order to study the effects on local meteorology and AQ. Figure 2 presents the land use for the existing situation (BASE) and for the scenario of expansion of the City Park (GREEN).
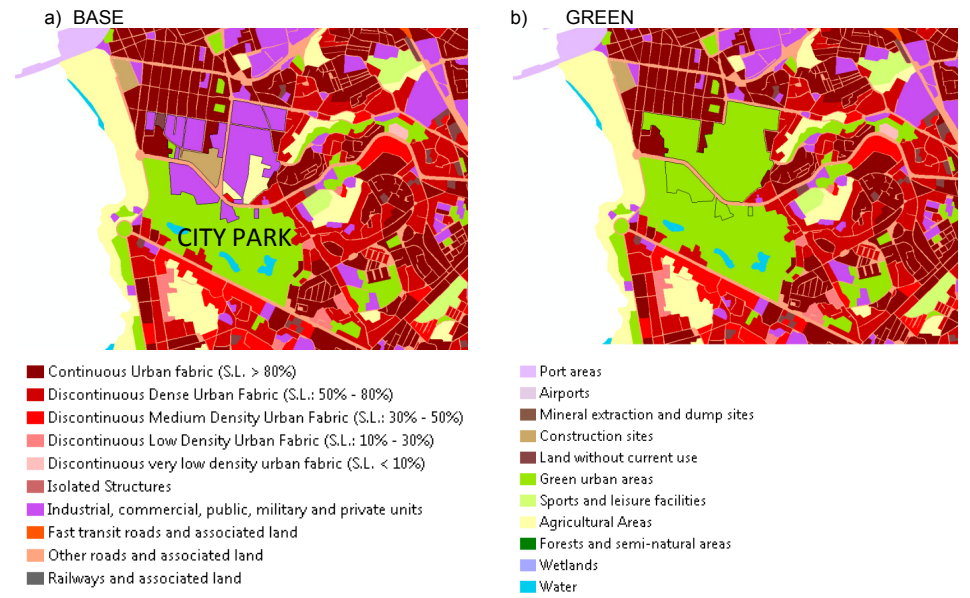

Figure 2: Study area land use for a) BASE and b) GREEN.

According to the Urban Atlas, the City Park currently has an area of 68.4 hectares, divided between 64.9 ha of green areas and 3.5 ha of aquatic surfaces. In the land use change scenario, the green area is enlarged to a total of 123 ha. This expansion is achieved through the conversion of land adjacent to the Park: 
industrial and commercial areas (45.2 ha), semi-natural and agricultural areas (6.1 ha) and unused ground set (6.5 ha).

\subsection{Results and discussion}

The effects of the expansion of the City Park in the meteorology were analysed in terms of temperature, wind speed and direction. Figure 3 shows the spatial distribution of the temperature differences between GREEN and BASE, obtained for August 1, at 13:00, corresponding to the simulation period for which the maximum differences were found. The largest decrease of temperatures is obtained in the City Park area, with maximum values of $-2.3^{\circ} \mathrm{C}$, while for the remaining domain differences vary between $-0.5^{\circ} \mathrm{C}$ and $+0.2^{\circ} \mathrm{C}$.

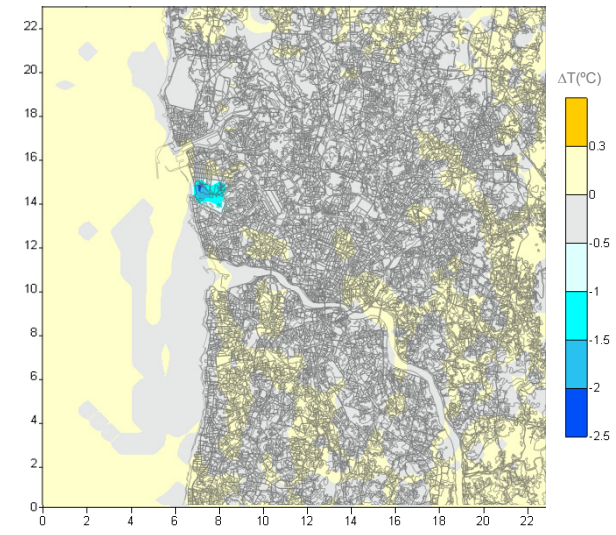

Figure 3: Temperature differences between GREEN and BASE for August 1, 13:00.

Figure 4 displays the hourly time-series of simulated temperature and wind speed in the City Park for BASE and GREEN. The GREEN scenario presents lower temperatures during practically the entire simulation period, including nocturnal cooling. Maximum differences reach $-1.6^{\circ} \mathrm{C}$ and $-2.3^{\circ} \mathrm{C}$, corresponding to the maximum daily simulated temperatures, for July $31^{\text {st }}$ and August $1^{\text {st }}$, respectively.

No significant differences in wind speed or direction (varying between NW and NE) were found the study area, besides an increase of $0.5 \mathrm{~m} \cdot \mathrm{s}^{-1}$ in the average wind speed for the GREEN scenario, mainly due to increases of the lower speeds.

The effects of the expansion of the City Park on the AQ were analysed in terms of the maximum concentrations of $\mathrm{NO}_{2}$ and $\mathrm{O}_{3}$ and the average concentrations of PM10. Table 1 presents the concentrations obtained for the study area for the two simulated days, for BASE and GREEN. It turns out that the simulated concentrations are similar, however GREEN features lower $\mathrm{O}_{3}$ concentrations $\left(-3\right.$ and $\left.-4 \mu \mathrm{g} . \mathrm{m}^{-3}\right)$ and, consequently, higher concentrations of $\mathrm{NO}_{2}\left(+2\right.$ and $\left.+5 \mu \mathrm{g} \cdot \mathrm{m}^{-3}\right)$. For PM10, differences are smaller than $1 \mu \mathrm{g} \cdot \mathrm{m}^{-3}$. 


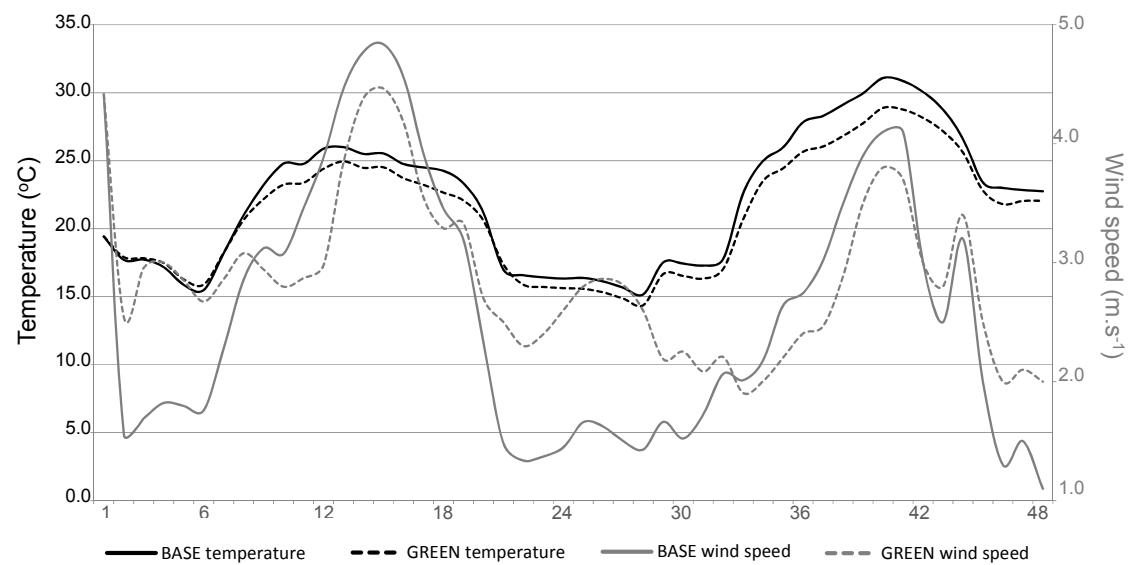

Figure 4: Time series for temperature and wind speed at the City Park for BASE and GREEN.

Table 1: $\quad$ Maximum and average daily concentrations $\left(\mu \mathrm{g} \cdot \mathrm{m}^{-3}\right)$ for BASE and GREEN.

\begin{tabular}{lcccccc}
\cline { 2 - 7 } & \multicolumn{4}{c}{ 31.JUL.2003 } & \multicolumn{2}{c}{ 1.AGT.2003 } \\
\cline { 2 - 7 } & {$\left[\mathrm{O}_{3}\right] \max$} & {$\left[\mathrm{NO}_{2}\right] \max$} & {$[\mathrm{PM} 10] \mathrm{avg}$} & {$\left[\mathrm{O}_{3}\right] \max$} & {$\left[\mathrm{NO}_{2}\right] \max$} & {$[\mathrm{PM} 10] \mathrm{avg}$} \\
\hline BASE & $\mathbf{1 5 4}$ & 161 & $\mathbf{7 2}$ & $\mathbf{1 6 7}$ & 161 & $\mathbf{9 0}$ \\
GREEN & 151 & $\mathbf{1 6 3}$ & 71 & 163 & $\mathbf{1 6 6}$ & 89 \\
\hline
\end{tabular}

The simulations conducted by the WRF-UCM-CAMx modelling system show that the expansion of Porto's City Park can result in a positive microclimatic effect. The applied modelling system proved to be an adequate and useful approach in linking the several spatial scales associated with the UHI effect. The results point to a decrease in temperature and an increase in wind speed during the night period. As regards $A Q$, concentration differences are negligible, and the photochemical model does not show sensitivity to the increase of the resolution to $500 \mathrm{~m}$.

\section{Urban wind comfort}

In addition to the introduction or expansion of urban green areas, other $\mathrm{CC}$ adaptation measures should also be considered with a view to combining several actions in achieving maximised urban resilience. With the expected sea-level rise, a consequence of $\mathrm{CC}$, the increased dynamic interactions between ocean surfaces and atmosphere will result in higher wind speeds, especially in large cities where the canyon effect, promoted by rows of tall buildings, tends to amplify incoming winds which may affect local wind comfort. For the 
classification of the adequacy of outdoor locations for pedestrian use, several criteria have been proposed in the literature. The common feature of these is the definition of a wind velocity threshold $(\mathrm{u})$, associated to particular pedestrian activities, and combined with the respective frequencies of occurrence within the studied periods. The main differences reside in the activities considered, the permissible velocity threshold, the inclusion of gust peaks and the tolerable frequencies of incidence.

Melbourne [10] developed a comfort criterion for 3 activities: long-term sitting $\left(\mathrm{u}=10 \mathrm{~m} \cdot \mathrm{s}^{-1}\right)$, short term sitting $\left(13 \mathrm{~m} \cdot \mathrm{s}^{-1}\right)$ and strolling $\left(16 \mathrm{~m} \cdot \mathrm{s}^{-1}\right)$ with an incidence of $0.022 \%$ ( 2 hours/year) common to all the described pedestrian actions. Lawson (1978) established a criterion based on the Beaufort wind scale for 4 activities: long-term sitting $\left(u=1.8 \mathrm{~m} . \mathrm{s}^{-1}\right)$, short-term sitting $\left(3.6 \mathrm{~m} . \mathrm{s}^{-1}\right)$, strolling $\left(5.3 \mathrm{~m} . \mathrm{s}^{-1}\right)$ and walking fast $\left(9.8 \mathrm{~m} . \mathrm{s}^{-1}\right)$, with a frequency of $2 \%$. In an alternative approach, using the same threshold velocity for all activities while varying frequencies of occurrence for each, Willemsen and Wisse [11] proposed a criterion which is currently employed as the Dutch National Standard (NEN $8100)$. Under this criterion, a velocity of $5 \mathrm{~m} . \mathrm{s}^{-1}$ is deliberated as the threshold for all pedestrian activities. With a view to incorporating wind comfort in tall building project approvals, local authorities have formulated city specific criteria, particularly in North America. Montreal [12] establishes critical mean wind speeds for winter $\left(4 \mathrm{~m} \cdot \mathrm{s}^{-1}\right)$ and summer $\left(6 \mathrm{~m} \cdot \mathrm{s}^{-1}\right)$, with frequencies dependent on area types (15\% for main streets, $25 \%$ for secondary streets and $10 \%$ for parks); while San Francisco [14] defines an effective wind velocity threshold of $11.67 \mathrm{~m} \cdot \mathrm{s}^{-1}$ at $0.01 \%$.

\subsection{Methodology}

\subsubsection{Modelling tool}

The numerical tool used for the study was the CFD model Fluent ${ }^{\circledR}[8,14,15]$. The study involves a pre-processing phase which consists of the definition and construction of the study domain as well as the analysis of the meteorological observations that lead to scenario development. Local wind comfort is posteriorly evaluated through the application of specific criterion to the obtained simulation results.

\subsubsection{Study area}

The Vila Galé Hotel, an $80 \mathrm{~m}$ high building located in the heart of the city, is a short distance to several historical monuments, a high-value commercial district and transport infrastructures, the area boasting high pedestrian attendance. Therefore, a pedestrian wind comfort analysis of the surrounding area is of significant relevance.

The 3D computational domain was defined using Fluent's CAD pre-processor Gambit, with all buildings of the domain being modelled, resulting in a built-up area of approximately $36 \mathrm{ha}(600 \mathrm{~m} \times 600 \mathrm{~m})$. For this purpose, the 3D coordinates of each building were extracted from the city's GIS data and BingMaps ${ }^{\circledR}$. An unstructured meshing scheme (TGrid type) is most indicated for 
irregular or complex geometries and was used for the discretization of the domain in over 5 million computational grid cells.

The numerical simulations were conducted following the best practice guidelines proposed under COST Action 732 [16].

\subsubsection{Meteorological scenarios definition}

The climatological time series ranges from 1951 to 1980, having been acquired from weather observations undertaken by a meteorological station located at Francisco Sá Carneiro International Airport, just over $12 \mathrm{~km}$ northeast of the northeast boundary of the computational domain. This resulted in 8 study scenarios, listed in Table 2, that represent typical meteorological conditions in the city. Excluding periods of non-measurement ( $7 \%$ incidence), the nominated study cases represent $93 \%$ of the time, thus providing a high representativeness of the atmospheric dynamics as well as contemplating the highest measured wind velocities during the period.

Table 2: $\quad$ Selected input meteorological scenarios.

\begin{tabular}{cccc}
\hline Scenario & $\begin{array}{c}\text { Wind } \\
\text { Direction }\end{array}$ & $\begin{array}{c}\text { Wind } \\
\text { velocity } \\
{\left[\mathrm{m.s}^{-1}\right]}\end{array}$ & $\begin{array}{c}\text { Wind } \\
\text { frequency } \\
{[\%]}\end{array}$ \\
\hline 1 & $\mathrm{~N}$ & 3.57 & 14.82 \\
2 & $\mathrm{NE}$ & 2.59 & 4.43 \\
3 & $\mathrm{E}$ & 3.79 & 18.83 \\
4 & $\mathrm{SE}$ & 3.75 & 5.99 \\
5 & $\mathrm{~S}$ & 5.76 & 10.11 \\
6 & $\mathrm{SW}$ & 4.92 & 8.52 \\
7 & $\mathrm{~W}$ & 4.18 & 12.62 \\
8 & $\mathrm{NW}$ & 4.99 & 17.72 \\
\hline
\end{tabular}

\subsection{Results and discussion}

In this work, the pedestrian wind comfort criterion proposed by Willemsen and Wisse [11], and largely disseminated in literature, was applied. Table 3 summarizes the threshold conditions employed for each activity as a function of the wind frequency.

Table 3: Dutch wind comfort criterion for pedestrian activities [11].

\begin{tabular}{cccc}
\hline $\begin{array}{c}\text { Frequency of } \\
\text { occurrence } \\
\left(\mathrm{u}>5 \mathrm{~m} \cdot \mathrm{s}^{-1}\right)[\%]\end{array}$ & Traversing & Strolling & Sitting \\
\hline$<2.5$ & Good & Good & Good \\
$2.5-5$ & Good & Good & Moderate \\
$5-10$ & Good & Moderate & Poor \\
$10-20$ & Moderate & Poor & Poor \\
$>20$ & Poor & Poor & Poor \\
\hline
\end{tabular}


Scenario 6 represents the most critical case in terms of wind velocities at an average pedestrian level of $1.5 \mathrm{~m}$. The incoming winds from the southwest are concentrated at the windward corners of the hotel generating an acceleration of the resulting downwash into horizontal motion, as can be observed in Figure 5 where mean velocities at these corners surpass the $6 \mathrm{~m} \cdot \mathrm{s}^{-1}$ mark despite a domain entry velocity of just under $5 \mathrm{~m} \cdot \mathrm{s}^{-1}$.

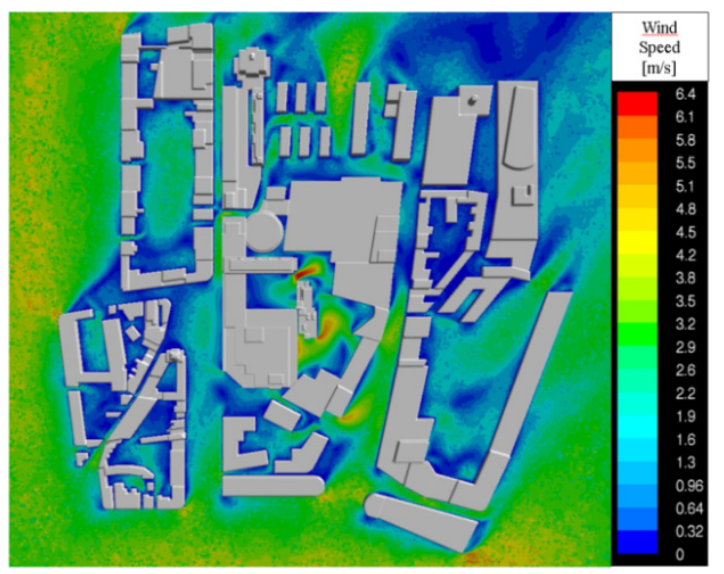

Figure 5: Pedestrian level wind speeds for scenario 6.

Figure 6 displays the corresponding pathlines in the hotel vicinity. As was observed in Figure 5, the threshold proposed by the Dutch wind comfort standard (Table 3 ) is surpassed in this scenario, which represents an annual frequency of $8.5 \%$. Therefore, under these conditions results indicate that the area is unsuitable for sitting and moderately uncomfortable for strolling. For the other scenarios, the wind velocity threshold is never reached, with the hotel surroundings being adequate for all pedestrian activities.

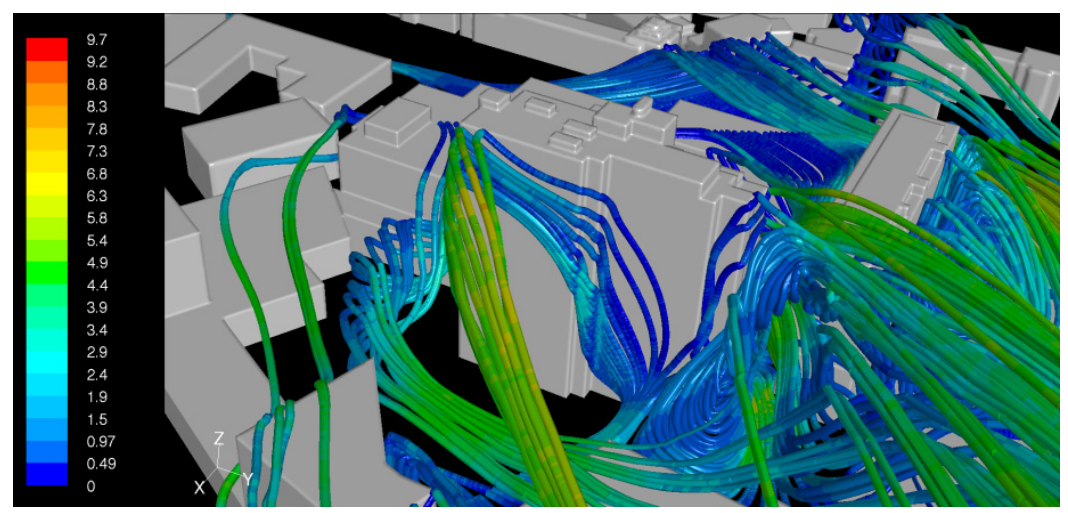

Figure 6: Pathlines in the hotel vicinity for scenario 6. 
An evaluation of the incorporation of measures that improve local wind comfort, namely windbreakers (artificial and natural) is currently underway. Consequently, the efficiency of their implementation may be obtained under comparison with the results for the present configuration.

\section{Final comments}

Although the meteorological benefits of the increased City Park obtained in this study are local, the potential of green urban areas for UHI mitigation should not be neglected. Instead, measures like the one implemented in this work should be combined with other mitigation measures in order to reach the highest mitigation potential. Other measures can be applied such as the widespread use of vegetation (e.g. green roofs and walls), or the use of new building and road materials to increase the albedo.

Increases in urban vegetated areas may also benefit wind comfort conditions for most pedestrian activities. As the present study shows, urban geometries can frequently induce the canyon effect in which incoming winds are forced to converge into channels, created by rows of buildings, accelerating horizontally in the process. At the micro-scale level, the correct application of natural windbreakers, such as trees or shrubs, promotes the mitigation of such effects and provides a friendlier environment for pedestrians. However, the positioning of these windbreakers is critical, as they may also act oppositely to the desired effect, hence the importance of CFD models in assisting authorities and stakeholders in decision-making.

\section{Acknowledgements}

This work was funded by FEDER funds, through the operational program COMPETE and by national funds, through the National Foundation for Science and Technology (FCT), in the framework of the project CLICURB (EXCL/AAG-MAA/0383/2012). The authors also wish to thank FCT for the Post-Doc Grants of Helena Martins (SFRH/BPD/66874/2009) and Jorge H. Amorim (SFRH/BPD/48121/2008).

\section{References}

[1] United Nations. World Urbanization Prospects: The 2007 Revision, 2007 (available online at http://esa.un.org/unup).

[2] Oke TR. The Energetic Basis of the Urban Heat Island. Q J Roy Meteor Soc 1982; 108: 1-24.

[3] Oke TR. The urban energy balance. Prog Phys Geog 1988; 12: 471-508.

[4] EEA. The application of models under the European Union's Air Quality Directive: A technical reference guide. EEA Technical Report 10/2011. Copenhagen: EEA; 2013. 
[5] Skamarock WC. Klemp JB. Dudhia J. Gill DO. Barker DM. Duda M. Huang X-Y. Wang W. Powers JG. A Description of the Advanced Research WRF Version 3. NCAR Technical Note; 2008.

[6] Morris RE. Yarwood G. Emery C. Koo B. Development and Application of the CAMx Regional One-Atmosphere Model to Treat Ozone, Particulate Matter, Visibility, Air Toxics and Mercury. Presented in 97th Annual Conference and Exhibition of the A\&WMA, June 2004, Indianapolis.

[7] Vautard R, Beekman M, Desplat J, Hodzic A, Morel, S. Air quality in Europe during the summer of 2003 as a prototype of air quality in a warmer climate. Comptes Rendus Geoscience 2007; 339: 747-763.

[8] Amorim, JH., Rodrigues, V., Tavares, R., Valente, J., Borrego, C. CFD modelling of the aerodynamic effect of trees on urban air pollution dispersion. Science of the Total Environ 2013. 461-462: 541-551.

[9] Martins H. Urban compaction or dispersion? An air quality modelling study. Atmos Environ 2012. 54: 60-72.

[10] Melbourne, WH. Criteria for environmental wind conditions. J. Wind Eng. Ind. Aerodyn. 1978. 3: 791-800.

[11] Willemsen, E., Wisse, JA. Design for wind comfort in The Netherlands: procedures, criteria and open research issues. J. Wind Eng. Ind. Aerodyn. 2007. 95: 1541-1550.

[12] Service de l'habitation et du développement urbain. Module gestion du développement. Cadre Réglementaire: arrondissement Ville-Marie. Ville de Montréal 1992.

[13] City and County of San Francisco. Municipal Planning Code, Vol. 1. Section 148: Reduction of ground-level wind currents in C-3 districts. Municipal Code Corporation (2006).

[14] Amorim, JH., Valente, J., Cascão, P., Pimentel, C., Miranda, AI., Borrego, C. Pedestrian exposure to air pollution in cities: modelling the effect of roadside trees. Advances in Meteorology 2013; DOI: 10.1155/2013/964904.

[15] Borrego, C., Tchepel, O., Costa, AM., Amorim, JH., Miranda, AI. Emission and dispersion modelling of Lisbon air quality at local scale. Atmos Environ 2003. 37: 5197-5205.

[16] Franke, J., Hellsten, A., Schlünzen, H., Carissimo, B. Best Practice Guideline for the CFD Simulation of Flows in the Urban Environment. COST Action 732, Quality Assurance and Improvement of Microscale Meteorological Models. COST Office 2007. p. 51. 